\title{
Assessment and prospects for improving the technical level of surface mining machines
}

\author{
Yuri Voronov ${ }^{1}$, Sergey Grishin ${ }^{1}$, Artyom Voronov ${ }^{1}$, Vladimir Romashko ${ }^{1}$, and Anton \\ Voronov $^{2}$ \\ ${ }^{1}$ T.F. Gorbachev Kuzbass State Technical University, Department of Road Transport, 650000 \\ Kemerovo, 28 Vesennya st., Russian Federation \\ ${ }^{2}$ Kuzbassrazrezugol Coal Company JSC, 650054 Kemerovo, 4a Pionersky blvd., Russian Federation
}

\begin{abstract}
Assessment of the technical level of surface mining machines is carried out according to a special method of expert-free assessment of mining machine quality, known as the G.I. Solod's technique. The technique is based on the basic principles of qualimetry and allows to assess functionally homogeneous machines of different sizes, types and designs based on the functional criterion of the machine that determines its main purpose. Assessment of the technical level of mining machines creates the basis for choosing priority areas for its improvement and development of scientifically-based methods for the optimal design of machines. In this regard, the aim of the work is a comprehensive assessment of the technical level of surface mining machines to increase it and optimize their parameters. For this, methods of mathematical modeling, statistics, data collection and processing, analysis and synthesis were used. The developed methodology for integrated assessment provides the ability to control the quality of a surface mining machine at all stages of its life cycle: design, manufacture, operation.
\end{abstract}

\section{Introduction}

As applied to the mechanical equipment of surface mines (drilling rigs, single-bucket excavators or shovels, mining trucks) and shovel-truck systems at surface mines, G.I. Solod's technique was used in [1-7]. The differences in the options of the technique in the indicated works consist in specific functional criteria and the set of indicators of the technical level. Moreover, the term "technical level" refers to the quality level of the machine at the design stage.

An integrated assessment of the technical level of surface mining machines includes the following steps:

- Selection of a functional criterion for assessing the technical level;

- Justification and determination of indicators of the technical level (or quality);

- Assessment of the technical level (or quality) of existing surface mining equipment fleets;

- Analysis of the results of assessing the technical level of machines and the selection of promising areas for its improvement. 


\section{Selection of a functional criterion}

Since the quality of a mining machine can show itself only when a machine performs its task in accordance with its purpose - when drilling holes in rocks with certain physical and mechanical properties, during excavation and transportation of material (overburden or minerals), then the machine cannot be considered in isolation from the material interacting with it. For such an assessment, it is necessary to have a functional criterion for the interaction of elements of the systems "drilling rig - rock", "excavator - material", "mining truck material - road" under the restrictions imposed by the external mining environment.

From the point of interaction, the main purpose of the mining machine is to ensure high productivity, the main property of the material is the ability to resist drilling, excavation, and transportation. The parameter of the machine that most determines the effectiveness of the interaction is its productivity $Q$; as the main parameter of the material, which most characterizes its ability to resist the fulfillment of this function, the specific energy of the mining machine $W$ to perform its main function in accordance with the purpose.

The product of the indicated main parameters for the machine and material

$$
\lambda=W \cdot Q
$$

makes a functional criterion for assessing the quality of surface mining machines $(\mathrm{kW})$.

The specific energy of a mining machine to perform its function is the minimum energy required for the destruction and removal of $1 \mathrm{~m}^{3}$ of rock from a hole (drilling rigs), digging and loading $1 \mathrm{~m}^{3}$ of material in one cycle (excavators), transportation of 1 ton of material along a $1 \mathrm{~km}$ long road with given profile (trucks). It should be completely determined by the physico-mechanical properties of the rock massif, material, characteristics of the supporting surface, and does not depend on the type, model, and design of the machine. Therefore, when comparing mining machines with different areas of rational use, the parameter $W$ will be a scale factor, which puts the auger and cone drilling rigs, all excavators and mining trucks (ore, coal or overburden carriers) on a par, allowing to compare their technical level and quality.

Depending on what performance will be used in determining the functional criterion, it can be used to assess the technical level of machines or the level of quality of their operation. To compare existing surface mining machines with each other and when designing new equipment, theoretical performance should be used in determining the functional criterion (1).

The specific energy of drilling should include two components: $W=W_{r}+W_{o}$, where $W_{r}, W_{o}$ are the specific energies of rock destruction and removal from the hole, $\mathrm{MJ} / \mathrm{m}^{3}$. The values of $W_{r}$ are given in the reference literature. The dependence for the specific energy of removal of fracture products from the hole was determined in [1] and has the form $W_{o}=$ $0,5 \rho_{p} g\left(\cos \alpha+f_{c} \sin \alpha\right) L_{c}$, where $\rho_{p}$ is the density of the drillable massif, $\mathrm{t} / \mathrm{m}^{3} ; g$ is the gravitational acceleration, $\mathrm{m} / \mathrm{s}^{2} ; \alpha$ is the angle of inclination of the hole to the vertical; $f_{c}$ is the coefficient of friction of the rock on the drill string; $L_{c}$ is the hole depth, $\mathrm{m}$.

Drilling performance can be determined by the following formula: $P_{T}=0,25 \pi D_{s}^{2} \vartheta_{T}$, where $D_{s}$ is the diameter of the borehole, $m ; \vartheta_{T}$ is the technical drilling speed, $\mathrm{m} / \mathrm{h}$.

The specific energy of material excavation is defined as the work spent by an excavator on digging material and loading it into a truck, per $1 \mathrm{~m}^{3}$ of excavator bucket capacity. The dependence for determining the specific energy of excavation was determined in [2] and has the following form $\left(\mathrm{kJ} / \mathrm{m}^{3}\right): W=k_{f}+0,5 \rho_{p} g\left(h_{k}+\frac{\pi n^{2} R_{v}^{2}}{22}\right)$, where $k_{f}$ is the specific digging resistance of the rock, $\mathrm{kPa} ; h_{k}$ is the maximum digging height of the excavator, $\mathrm{m}$; $n$ is the rotational speed of the turntable, $\min ^{-1} ; R_{v}$ is the discharge radius, $\mathrm{m}$. 
Excavator productivity per $1 \mathrm{~m}^{3}$ of bucket capacity can be determined by the wellknown formula $\left[\mathrm{m}^{3} /\left(\mathrm{h} \cdot \mathrm{m}^{3}\right)\right]: \mathrm{P}_{\mathrm{T}}=3600 / \mathrm{t}_{\mathrm{c}}$, where $\mathrm{t}_{\mathrm{c}}$ is the estimated working cycle duration, s. It is given in the technical characteristics of single-bucket excavators, for example, in $[8-10]$.

The specific energy of material transportation is defined as the transportation work per 1 $\mathrm{t} \cdot \mathrm{km}$. This work is carried out due to the traction force of the truck and is aimed at overcoming the forces of resistance to movement. The traction force that a vehicle can realize is determined by the characteristics of its engine and transmission and does not depend on the presence or absence of material in the body. The force of resistance to the movement of the truck directly depends on its load. The dependence for determining the specific transportation energy was determined in [4] and has the form $(\mathrm{MJ} / \mathrm{t} \cdot \mathrm{km}): W=\frac{g\left[f_{c}+i_{\max }\left(2 k_{T}+1\right)\right]}{\sqrt{1+i_{\text {max }}^{2}}}$, where $i_{\text {max }}$ is the maximum slope of the lift overcome by the truck; $f_{c}$ is the coefficient of rolling resistance of the truck on the road; $k_{T}$ is the tare coefficient.

The performance of the truck is defined as the product of its payload and the average technical speed of its movement along the route per 1 auto-ton [4]. It has the following form $(\mathrm{kW} / \mathrm{kN}): P_{T}=0,56 \frac{N_{d v}}{m_{g r}} \cdot \frac{\sqrt{1+i_{\max }^{2}}}{g\left[i_{\max }+f_{c}\left(2 k_{T}+1\right)\right]}$, where $N_{d v}$ is the power of the truck engine, $\mathrm{kW}$.

Substituting the corresponding dependences in the formula (1), we obtain the expressions for the functional criterion of each mining machine.

\section{Justification and determination of indicators of the technical level}

The indicators characterizing the technical level of the machine are established as a result of a detailed analysis of the operations performed by this machine in the technological process. The initial full set of indicators is then subjected to gradual reduction according to the criteria of consistency, representativeness, subordination to the goal of quality assessment, expressed as a functional criterion.

For drilling rigs, the following technical level indicators have been adopted: the power spent on face destruction $N_{r}$ and cleaning the hole $N_{t r}$; mass index (total material consumption) of the rig $M$; comparative material consumption of the rig (mass coefficient) $m_{c}$; total drilling depth $L_{c}$ and drilling depth in one pass $l_{p r}$; speeds of maneuvering operations $v_{\text {man }}$ and movement $v_{\text {per }}$; coefficient of technical use of the rig $k_{t i}$; coefficient of mechanization level of auxiliary operations $k_{u m}$.

For single-bucket excavators, the characteristic indicators of the technical level are: specific energy consumption $E_{u}$ and metal intensity $k_{M}$ of the machine; specific digging force $k_{f}^{e}$; specific working dimensions of the shovel $k_{r}^{h k}$ and $k_{r}^{R k}$, which determine the height and width of the face; excavator adjusted life $T_{r}$, as an integral indicator of reliability.

For mining trucks, the characteristic single indicators are: specific load capacity of the truck $m_{g r}^{u d}$; density of its layout $\rho_{k}$; the mass coefficient of the truck $k_{M}$; power reserve $L_{h}$; reduced turning radius $R_{p r}$; maximum speed of the truck $v_{\text {max }}$; standard mileage of the $\operatorname{truck} T_{r}$.

All of these indicators are available for determination at the earliest stages of machine design. Depending on more specific conditions and requirements, the introduction of additional indicators is possible. 


\section{Assessment and determination of directions for improving the technical level}

Assessment of the technical level of existing mining equipment fleets is carried out under the following conditions. Of the total number of models we stand out machines that are widely used at surface mines. In order to compare the technical level of domestic surface mining machines with foreign ones, sufficiently developed and widely used in the world machine designs of leading companies in this field are accepted for consideration. In the group of drilling rigs, a total of 15 models of drilling rigs were considered, of which 10 were domestic models, and 5 models of Bucyrus-Erie machines. They cover the range of drilling holes from 125 to $381 \mathrm{~mm}$ in diameter and from 24 to $60 \mathrm{~m}$ in depth. To assess the technical level of mining excavators, 24 machines of all sizes with a bucket capacity of 5,2 $\mathrm{m}^{3}$ to $45 \mathrm{~m}^{3}$ were selected, of which 5 excavators were manufactured by OMZ, as well as 19 machines from foreign companies: American Caterpillar, Japanese Komatsu and Hitachi, German Liebherr and Swiss Terex O\&K. Among the trucks, a total of 22 models were considered. These are 14 models of BelAZ trucks with a payload of 30 to 320 tons, 6 models of Caterpillar trucks with a payload of 36,3 tons and 218 tons, and one model of Komatsu (120 tons) and Unit Rig trucks (181,4 tons).

A general analysis of the results of the calculation of a generalized indicator of the technical level of drilling rigs indicates a general low technical level of the domestic drilling rig fleet at surface mines. The technical level $k$ of the considered Bucyrus-Erie machines is almost 2 times higher than the domestic ones. Domestic machines are inferior to foreign ones in almost all respects, and especially in terms of characterizing the quality of auxiliary operations, the level of mechanization and reliability. The degree of imbalance in the parameters is also high in domestic machines (50\% against $18 \%)$.

The generalized indicator of the technical level of all mining hydraulic excavators is above 0,5 . This indicates their fairly high technical level. The average technical level of the considered group of excavators is $k=0,764$. The average level of domestic machines is only slightly $3 \%$ lower than that of foreign companies.

Like for excavators, the aggregate indicator for all mining trucks is higher than 0,5 . The average technical level of the considered group of machines is 0,695 . Like for excavators, the technical level of BelAZ trucks and foreign trucks is almost the same. This means that from the point of design scheme perfection and availability of new ideas and solutions, BelAZ trucks practically do not differ from foreign machines (this also applies to excavators).

The analysis of the technical level indicator of drilling rigs, which characterizes the rationality of using the power spent on destruction, shows that the group of domestic drilling rigs has a total technical level of 0,655 , while in the group of foreign rigs this indicator approaches 1 , amounting to 0,961 .

From the values of the indicator reflecting the efficiency of using the power spent on cleaning the hole, it can be seen that screw machines have higher values of this indicator and much lower values are roller cone drilling machines, in which the hole is cleaned by blowing with compressed air. This indicates a very high energy intensity of transportation of fracture products from the hole with compressed air and the need to switch to a screwpneumatic cleaning method, which allows to reduce air consumption compared to purging by $35-40 \%$ [11].

An analysis of the values of the indicator characterizing the correspondence of the weight of the drilling rig and the axial force developed by the feed system shows that most of the machines are excessively heavy. It should also be noted that machines with a lower 
rotator arrangement and a cartridge feed circuit have better values of this indicator compared to machines with a movable rotator.

From the analysis of indicators characterizing the quality of auxiliary operations, it clearly follows that domestic machines are significantly inferior to foreign ones. This indicates a low level of mechanization of auxiliary operations and unbalanced parameters. Domestic rigs more than double the level of mechanization of auxiliary operations, and almost double the reliability of domestic drilling rigs compared to foreign ones. All this indicates the need for large-scale work on this issue too.

The main reserves for increasing the technical level of excavators are: an increase in the specific digging force, the largest specific digging radius, as well as a decrease in specific metal consumption and specific energy consumption. For domestic excavators, the main reserve is to increase the resource.

An analysis of the technical level of mining trucks shows that BelAZ trucks are ahead of foreign ones in specific payload, layout density, mass coefficient and reduced turning radius; and lag behind in fuel range, maximum speed and, especially, in resource mileage.

BelAZ and foreign trucks are about the same in specific payload, and BelAZ trucks even outperform foreign machines by $6,4 \%$. The second indicator, according to which both domestic and foreign trucks have high values, is the layout density (compactness) of the truck. The overall technical level of this indicator for BelAZ trucks is $11,2 \%$ higher than for foreign vehicles. This means that the layout of all the machines is quite rational, and foreign trucks have a more "loose" layout. Analysis of the mass indicator indicates the need for its reduction. Moreover, BelAZ machines even win a little (by 9,8\%). And the last indicator by which BelAZ trucks surpass foreign ones is the indicator characterizing the maneuverability of the machine. BelAZ trucks are $8,7 \%$ higher than foreign ones.

In terms of movement autonomy, BelAZ trucks are lagging behind foreign vehicles. The main reason is that BelAZ trucks have less efficient engines in combination with smaller fuel tanks. BelAZ trucks are even lagging behind foreign machines in terms of speed, they are $8,7 \%$ less mobile compared to foreign vehicles, even with a greater power supply. The most significant lag of BelAZ trucks from foreign-made ones takes place in terms of reliability and durability. BelAZ trucks are on average $27,5 \%$ less durable than foreign machines. This is due to the higher quality of foreign truck manufacturing, as well as higher requirements for the reliability of equipment abroad [12].

A general analysis of the results of calculating the performance of mining trucks and excavators shows that machine models with a higher energy capacity and also a lower dead weight are technically more advanced. This suggests that the technical policy when creating new machines of a larger size by further upgrading existing structures without significant qualitative changes has outlived itself. Empiricism in the design also will not give serious qualitative changes in the future. As analysis shows, new approaches to machine design should be applied, new materials should be used, reliability should be increased, and parameters should be balanced.

\section{Conclusion}

The basis for choosing priority areas for increasing the technical level of surface mining machines is a functional criterion specific to each type of machine, as well as a set of indicators selected depending on the degree of their influence on the performance of the respective machine. An analysis of the technical level of surface mining machines allows to conclude that its increase can be achieved through the development of scientifically based optimal design methods that allow to determine and optimally balance their parameters. 


\section{References}

1. Y. E. Voronov, Optimal design of open-pit mining machines (Innovative Engineering, Moscow, 2015)

2. P. A. Zykov, Increasing the technical level of open-pit hydraulic shovels at the design stage (Kuzbass State Technical University, Kemerovo, 2013)

3. A. V. Bujankin, Integrated assessment and prediction of indicators of mining truck operation quality (Kuzbass State Technical University, Kemerovo, 2004)

4. S. V. Basmanov, Optimization of parameters of mining trucks for increasing its technical level (Kuzbass State Technical University, Kemerovo, 2012)

5. Y. Voronov, A. Voronov, E3S Web Conf., 21, 01023 (2017)

6. Yu. Voronov, An. Voronov, Ar. Voronov, E3S Web Conf. 105, 01048 (2019)

7. An. Voronov, Yu. Voronov, Ar. Voronov, N. Demirel, E3S Web Conf. 105, 01058 (2019)

8. Y. E. Voronov, Rational Modes (Kemerovo, Kuzbass Polytechnic Institute, 1984)

9. S. V. Mkhatshwa, J. S. Afr. I. Min. Metall., 109, 223-232 (2009)

10. G. Lumley, Trends in performance of open cut mining equipment (GBI Mining Intelligence, 2012)

11. A. N. Egorov, V.T. Voytov, Mining Journal, 4-5, 102 (2003)

12. A. A. Kuleshov, Mining Journal, 1, 43 (2000) 